\title{
No plant is an island
}

\section{Plants exist within a complex network of interactions with organisms both closely and distantly related to them. That none can survive 'entire of itself' is as true of plant science as the plants we study.}

Cooperation is inherent to the biology of plants, at every scale and from the earliest of times. The sedentary lifestyle of most plants may contribute to this tendency. While animals have evolved sophisticated systems for locomotion, allowing them to move through the environment altering their behaviour to suit their current locations, plants have needed to specialize in the activity most profitable for where they are growing. They must rely on neighbours for tasks that they are incapable of doing themselves.

All eukaryotic life arose from a collaboration of two prokaryotes, one of which, probably a purple nonsulphur bacteria, became engulfed by the other and subsequently evolved into mitochondria. But plants went further by engaging with another prokaryote, most likely a cyanobacterium, to perform the role of power generator and become the chloroplast. This occurred too far in the past to be studied directly but the somewhat analogous situation of lichen might provide a window into such events.

Lichens were thought to be a symbiotic amalgam of a fungus and a cyanobacterium or other photosynthetic prokaryote. Free-living members of lichen partnerships can be found, yet attempts to create artificial lichens have failed to produce the more complicated aspects of natural lichens' body plans. A recent paper in Science $^{1}$ may explain this lack of success as it identifies a third partner in this intimate relationship. Species of basidiomycetes have been found in the cortex of not one but hundreds of lichens from over 50 genera. These yeasts, if not an essential partner in the make-up of lichens, seem to at least be very frequent participants that had been overlooked for decades until a transcriptomic approach revealed their importance.

Of course the endosymbiosis of chloroplasts and mitochondria are not the only symbiotic relationships in which plants are engaged. Below the ground, plant roots are intimately associated with mycorrhizal fungi from which they derive many essential nutrients, most notably nitrate, in exchange for complex organic compounds of value to the fungi. This association can be so beneficial to some plants that they dispense with other modes of nutrition.

Orchids have seeds devoid of endosperm, allowing the plants to produce thousands or even millions of microscopic seeds - Anoectochilus imitans, for example, has seeds a mere $50 \mu \mathrm{m}$ in length. Orchid seeds can thus be blown on the wind for hundreds and even thousands of miles, allowing them to easily cross oceans. Famously, after the catastrophic eruption of Krakatoa in August 1883, orchids were among the first species to resettle. With no endosperm to fuel their germination, orchid seeds must land on the hyphae of a species of basidiomycete and live symbiotically with it, at least during their initial stages of development. Yet some species of orchid, for example the bird's nest orchid (Neottia nidus-avis), never produce leaves and rely on their symbiotic partner as their only carbon source.

The interactions of plant roots with mycorrhizae are so extensive that in established and stable ecosystems, such as forests, they form an interconnected network linking trees not only to the fungi but through them to other trees. Earlier this year it was shown that this network allows the transfer of carbon between mature trees $^{2}$, even of different species, following up on work from the late 1990s showing that such transfer was possible in saplings ${ }^{3}$. It is appealing to contemplate that other material and potentially signals could be transferred by what has been dubbed the 'wood-wide web'. One contributor to a recent edition of National Public Radio's Radiolab (From Tree to Shining Tree http:// go.nature.com/2bb23y5; 30 July 2016) even went so far as to draw an analogy between a forest's wood-wide web and a brain.

Many exchanges are less tangible than that between a tree and its mycorrhizal supporters. Insects, mammals, birds and other animals are involved in both pollination and dispersal of seeds. Sometimes this is inadvertent but often plants pay for the services they receive with nectar, in the case of pollination, or with the edible flesh of the fruits and nuts that encase so many seeds. Nectar can also be used as an incentive to recruit 'mercenaries' to help support a plant against attack. Such is the case with bittersweet nightshade,
Solanum dulcamara, a part of whose defence against herbivory by slugs and beetles is to 'bleed' sugary solutions from the resulting wounds, attracting ants to combat the threat ${ }^{4}$. It could be that this was the ancestral condition that has seen the development of extrafloral nectaries in a number of plant species. Like root exudates for fungi, nectar can be considered the currency used by plants to reimburse insects for services rendered.

Naturally all interactions between plants and members of other species are not benign. There are cheats who profit from the relationships while failing to contribute: parasites and pathogens. But it is becoming increasingly apparent that the mechanisms employed by plants to prevent themselves falling victim to such fraudulent encounters are related to the routes by which beneficial relationships are established. Perhaps we should be considering plants' responses to invaders as less like a military campaign and more like the negotiation between parties trying to establish a trade deal. Plants do not construct walls to exclude all comers or oppose the free movement of goods and services.

Such a spirit of cooperation extends to plant biologists themselves, as to all branches of science. Looking at this issue of Nature Plants alone, the work presented involves 79 authors from 32 institutes across 11 countries on 5 continents. If we could count the countries of birth of those authors, or their nationalities, there is little doubt that the number would be far higher than 11 as the nature of science as a career is one of transnational collaboration and mobility.

Without the relatively easy transfer of information, practical knowledge and personnel across national and international boundaries, scientific progress, so vital to the future of humanity, will be much slower, if not completely stalled. Let us hope that despite the current climate of political uncertainty nothing is done to damage the symbiosis of research.

\footnotetext{
References

1. Spribille, T. et al. Science 353, 488-492 (2016).

2. Klein, T., Siegwolf, R. T. W. \& Körner, C. Science 352, 342-344 (2016).

3. Simard, S. W. et al. Nature 388, 579-582 (1997).

4. Lortzing, T. et al. Nat. Plants 2, 16056 (2016).
} 